\title{
PRACTICAL STABILITY OF CAPUTO FRACTIONAL DIFFERENTIAL EQUATIONS BY LYAPUNOV FUNCTIONS
}

\author{
Ravi AgArwal, S. Hristova And D. O’REgAN
}

\begin{abstract}
The practical stability of a nonlinear nonautonomous Caputo fractional differential equation is studied using Lyapunov like functions. The novelty of this paper is based on the new definition of the derivative of a Lyapunov like function along the given fractional differential equation. Comparison results using this definition for scalar fractional differential equations are presented. Several sufficient conditions for practical stability, practical quasi stability, strongly practical stability of the zero solution and the corresponding uniform types of practical stability are established.
\end{abstract}

Mathematics subject classification (2010): 34A34, 34A08, 34D20.

Keywords and phrases: practical stability, strongly practical stability, Lyapunov functions, Caputo derivatives, fractional differential equations.

\section{REFERENCES}

[1] R. Agarwal, D. O'Regan and S. Hristova, Stability of Caputo fractional differential equations by Lyapunov functions, Appl. Math. (accepted).

[2] N. Aguila-Camacho, M. A. Duarte-Mermoudand J. A. Gallegos, Lyapunov functions for fractional order systems, Comm. Nonlinear Sci. Numer. Simul., 19 (2014), 2951-2957.

[3] D. Bainov, A. Dishliev and I. Stamova, Practical stability of the solutions of impulsive sytems of differential difference equations via the method of comparison and some applications to population dynamics, ANZIAM J., 43, (2002), 525-539.

[4] D. Baleanu And O. G. Mustafa, On the global existence of solutions to a class of fractional differential equations, Comput. Math. Appl. 59, (2010), 1835-1841.

[5] S. R. Bernfeld. And V. LaKshmikantham, Practical stability and Lyapunov functions, Tohoku Math. J., 32, (1980), 607-613.

[6] SH. DAs, Functional Fractional Calculus, Springer-Verlag Berlin Heidelberg, 2011.

[7] J. V. DEVI , F.A. MC RAE AND Z. DRICI, Variational Lyapunov method for fractional differential equations, Comput. Math. Appl., 64 (2012), 2982-2989.

[8] K. Diethelm, The Analysis of Fractional Differential Equations, Springer-Verlag Berlin Heidelberg, 2010.

[9] M. A. Duarte-Mermoud, N. Aguila-Camacho, J. A. Gallegos and R. Castro-Linares, Using general quadratic Lyapunov functions to prove Lyapunov uniform stability for fractional order systems, Comm. Nonlinear Sci. Numer. Simul., 22 (2015), 650-659.

[10] J. HeNDERSON AND S. HRISTOVA, Eventual practical stability and cone valued Lyapunov functions for differential equations with "Maxima", Commun. Appl. Anal., 14, 4, (2010), 515-524.

[11] S. G. HRISTOVA, Practical stability and cone valued Lyapunov functions for differential equations with "maxima", Int. J. Pure Appl. Math, 57, 3, (2009), 313-323.

[12] S. G. Hristova and K. Stefanova, Practical stability of impulsive differential equations with "supremum" by integral inequalities, Eur. J. Pure Appl. Math., 5, 1 (2012), 30-44.

[13] S. HRistova, Generalization of practical stability for delay differential equations with respect to initial time difference, AIP Conf. Proc. 1570, 313 (2013).

[14] J. B. Hu, G.P. LU, S.B. ZHANG AND L.-D, ZHAO, Lyapunov stability theorem about fractional system without and with delay, Commun. Nonlinear Sci. Numer. Simulat., 20 (2015), 905-913. 
[15] T. KaczoreK, Practical stability and asymptotic stability of positive fractional 2D linear systems, Asian J. Control, 12, 2, (2010) 200-207.

[16] V. Lakshmikantham, S. Leela And J.V. Devi, Theory of Fractional Dynamical Systems, Cambridge Scientific Publishers, 2009.

[17] V. Lakshmikantham, S. Leela and A. A. Martynyuk, Practical Stability of Nonlinear Systems, World Scientific, Singapore, 1990.

[18] V. Lakshmikantham, S. Leela and M. Sambandham, Lyapunov theory for fractional differential equations, Commun. Appl. Anal. 12, 4, (2008), 365-376.

[19] V. LAKShmikAntham AND Y. Zhang, Strict practical stability of delay differential equation, Appl. Math. Comput. 118, 2-3, (2001) 275-285.

[20] J. La Salle And S. Lefschetz, Stability by Lyapunov's Direct Method and Applications, Academic Press, New York, 1961.

[21] A. A. Martynyuk, On practical stability of hybrid systems, Appl. Mech. 25, (1989), 101-107. (in Russian).

[22] A. A. Martynyuk, Practical stability of motion, Naukova Dumka, Kiev, 1983. (in Russian)

[23] C. Li, D. QIAn And Y. Chen, On Riemann-Liouville and Caputo Derivatives, Discrete Dynamics in Nature and Society, Vol. 2011, Article ID 562494, 15 pages.

[24] Y. Li, Y. Chen ANd I. Podlubny, Stability of fractional-order nonlinear dynamic systems: Lyapunov direct method and generalized Mittag-Leffler stability, Comput. Math. Appl. 59, (2010), 18101821.

[25] I. Podlubny, Fractional Differential Equations, Academic Press, San Diego, 1999.

[26] G. SAmko, A.A. Kilbas And O.I. Marichev, Fractional Integrals and Derivatives: Theory and Applications, Gordon and Breach, 1993.

[27] J.C. Trigeassou, N. Maamri, J. Sabatier and A. Oustaloup, A Lyapunov approach to the stability of fractional differential equations, Signal Processing, 91, (2011), 437-445.

[28] P. Wang And W. Sun, Practical Stability in terms of Two Measures for Set Differential Equations on Time Scales, The Scientific World Journal 2014 (2014), Article ID 241034, 7 pages. 